Jesper Tang Nielsen

\title{
Die kognitive Dimension des Kreuzes
}

Zur Deutung des Todes Jesu im Johannesevangelium

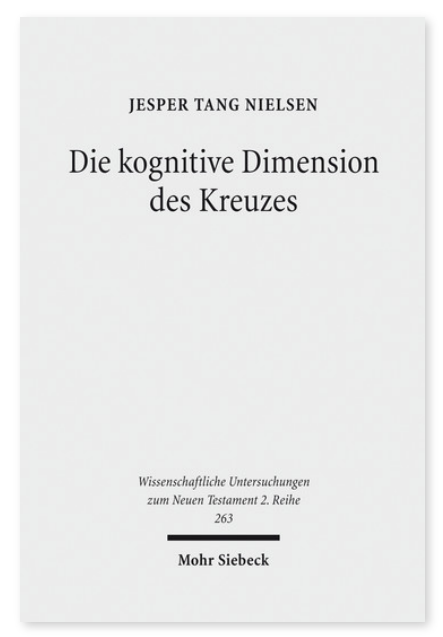

2009. XIII, 335 Seiten. WUNT II 263

ISBN 978-3-16-151606-1

DOI 10.1628/978-3-16-151606-1

eBook PDF 89,00€

ISBN 978-3-16-150017-6

fadengeheftete Broschur 89,00€
Einige Exegeten behaupten, dass der Tod Jesu im Johannesevangelium bedeutungslos ist. Andere meinen, dass das Johannesevangelium eine Kreuzestheologie vertritt.

Angesichts dieser Forschungssituation unternimmt Jesper Tang Nielsen den Versuch, die Funktion des Todes in den narrativen Strukturen des Vierten Evangeliums zu bestimmen. Aufgrund einer semiotischen Interpretation von Aristoteles' Poetik trennt er dabei die kognitive von der pragmatischen Dimension der Erzählung.

Es zeigt sich, dass der Tod Jesu vor allem in der kognitiven Dimension von vorrangiger Bedeutung ist. Er ist die unerlässliche Voraussetzung für die endgültige Anerkennung des Gottessohnes. Vor diesem Hintergrund kann er als Ursache der Sammlung der glaubenden Gemeinde und als Ursprung ihres Kultes dargestellt werden. So ist der Tod Jesu im Johannesevangelium weder bedeutungslos, noch passt er in die traditionellen theologischen Kategorien.

Jesper Tang Nielsen Born 1971, 2003 PhD; since 2007 Associate Professor of New Testament at the University of Copenhagen.

Jetzt bestellen:

https://mohrsiebeck.com/buch/die-kognitive-dimension-des-kreuzes-9783161516061?no_cache=1

order@mohrsiebeck.com

Telefon: +49 (0)7071-923-17

Telefax: +49 (0)7071-51104 